\title{
Abstracts of papers presented at the 11 th annual meeting of the Psychonomic Society, November 5, 6, and 7, 1970, Hilton Palacio del Rio, San Antonio, Texas
}

VERBAL PROCESSES

$9: 15-9: 25(1)$

Modality of Similarity and Hearing Ability, DORIS V. ALLEN, Wayne State University -Children representing five levels of hearing ability learned visually presented lists differing in implicit modality of cue (auditory vs visual) with either written or oral responses. A significant effect due to cues, with visual easier, and a Cues by Hearing Ability interaction were obtained. Mild hearing losses showed the greatest effect of cues.

$$
9: 25-9: 35(2)
$$

The Two Meanings of Abstractness. R. KAMMANN \& L. A. STREETER, Bell Telephone Labs $-\mathrm{Ss}$ constructed word hierarchies using 925 nouns rated for concreteness by Paivio, Yuille, \& Madigan. The analysis revealed substantial variation among conceptual hierarchies but little variation between superordinates and subordinates within hierarchies. Paivio's ratings of abstractness appear to be independent of Brown's (1958) definition of the abstract-concrete dimension.

$$
\text { 9:40-9:55 (3) }
$$

Mediation as a Basis for Stimulus Selection in Paired-Associate Learning. RUDOLPH W. SCHULZ \& PHILIP W. ZITZELMAN, University of Iowa-This study was designed to answer the following question: Would stimulus selection occur in a paired-associate mediation paradigm where the basis for selection was the opportunity to utilize a mediating association? The answer is, yes.

$$
\text { 9:55-10:05 (4) }
$$

Affect Conditioning in a PA Learning Task. HUGH McGINLEY, University of Wyoming, \& BARRY LAYTON, University of Manitoba (sponsored by John Zubek)-Six CVC-adjective pairs of either positive or negative affect categories were presented in a PA task for 1,3 , or 5 trials. Following presentation, Ss rated the CVCs on 7-interval bipolar adjectival scales, recalled pairs, and filled out CVC-adjective category and CVC rating-task contingency questionnaires. Affect conditioning (bipolar scales) occurred for both CVC-adjective category aware and unaware Ss. No Ss indicated CVC rating-task contingency awareness.

\section{BREAK}

$10: 25-10: 40(5)$

The Effect of Verb Meaning on the Connotative Meaning of Sentence Subjects. W. E. GUMENIK \& R. DOLINSKY, University of Toledo-Good-bad ratings of CVCs used as sentence subjects were made in the context of good or bad predicate verbs and good, neutral, bad, or understood (omitted) noun objects. Evaluative ratings of sentence subjects were similar to the predicate verbs, except with bad objects, in which case they were opposite.

$$
\text { 10:40-10:55 (6) }
$$

A Developmental Study of Syntactic and Semantic Clustering in Free Recall. JOSEPH H. DANKS, Kent State University (sponsored by David C. Riccio)-Twenty words were aurally presented to first-, third-, seventh-grade, and college students for eight trials of oral free recall. Nouns and verbs were selected from two conceptual categories, clothing and vehicles. Clustering according to semantic classes increased markedly with age, while there was only a minimal increase in syntactic clustering.
11:00-11:15 (7)

Distinctive Feature Coding Strategies in STM. RONALD A. COLE, University of Waterloo (sponsored by Philip Merikle)-Phonemic encoding by distinctive features was investigated during the serial recall of consonant $(C)$, vowel (V), or consonant-vowel (CV) sequences of 5,6 , or 7 phonemes. Distinctive feature analyses showed that the coding of phonemes is dependent on the linguistic context (V vs CV) and the serial position of the phoneme, but is independent of the number of phonemes to be recalled.

$$
11: 15-11: 35(8)
$$

Words as Phonological Sequences, DOUGLAS $L$. NELSON, University of South Florida-A series of paired-associate experiments determining the conditions under which stimulus words are apparently coded as phonological serial sequences will be reported. Variables manipulated include locus of letter identity, meaningfulness, modality, articulation, and characteristics of the response.

\section{1:40-11:50(9)}

Bilingual Verbal Discrimination Transfer: Implications for Verbal Discrimination Theory. DONALD H. KAUSLER \& SYLVIA F. KOLLASCH, Saint Louis University-A recognition model for verbal discrimination (VD) learning and transfer identifies frequency-of-response tags stored with features of the representations of list wrong (W) and right (R) words as the basis for intrapair W-R discriminations and interlist transfer effects. The $W_{1}-R_{1}$, $\mathrm{W}_{2}-\mathrm{R}_{1}$ transfer paradigm served to test the model when bilingual $S s$ were used and the $R_{1}-$ to- $R_{1}$ relationship consisted of English-to-Spanish and Spanish-to-English translations. Significant positive transfer (relative to a $\mathrm{W}_{1}-\mathrm{R}_{1}, \mathrm{~W}_{2}-\mathrm{R}_{2}$ control) occurred in the Spanish (List $1 \mathrm{R}$ word) to English translation (List $2 \mathrm{R}$ word) direction, but not in the English (List $1 \mathrm{R}$ word) to Spanish translation (List $2 \mathrm{R}$ word) direction.

\section{VISION (GENERAL)}

\section{8:45-9:05 (31)}

Empirical Laws for Brightness Discrimination Thresholds as a Function of Time Between Two Identical Flash Increments. ROBERT M. HERRICK, Naval Air Development Center-The literature (Granit \& Davis, Clark \& Blackwell, Bouman \& Van den Brink, Davy, Ikeda, etc.) suggests several contradictory formulations for two-flash brightness discrimination experiments. The contradictions will be resolved, empirical laws will be given, and the two-flash threshold will be related to the single-flash threshold.

\section{9:05-9:20 (32)}

Rhodopsin and Rod Dark Adaptation. W. A. H. RUSHTON \& DIANE SPITZER, Florida State University (sponsored by H. D. Baker, read by Diane Spitzer)-The amount of rhodopsin bleached and the subsequent course of regeneration were measured by retinal densitometry for various strengths of illumination. Log threshold curves were found to correspond to rhodopsin regeneration for bleachings from $100 \%$ to $7 \%$. When the amount of rhodopsin bleached was less than $7 \%$, the log threshold was initially raised above the value expected from the rhodopsin regeneration.

$$
\text { 9:25-9:40 (33) }
$$

Foveal Letter Recognition: Masking Unmasked. LESLIE 
HENDERSON \& MICHAEL L. MATTHEWS, University of Guelph (read by M. L. Matthews)-Recognition probabilities for briefly presented single letters and for single letters centered in a row of nine letters are obtained. Letters centered in the row are found to have higher recognition probabilities than single letters. The nature of this interaction with respect to letter specificity, contour interaction, and spatial arrangement is considered in terms of sensory and criterial changes.

\section{9:40-9:55 (34)}

Masking of Spatial Gratings by Filtered One-Dimensiona Visual Noise. B. JULESZ \& C. F. STROMEYER III, Bell Telephone Labs, Murray Hill, N.J.-Vertical stripes were displayed on a monitor whose brightness values in the horizontal direction were given by a Gaussian distribution. This one-dimensional noise passed through a band-rejection filter. The masking of an added vertical sinusoidal grating depended on whether its spatial frequency fell inside or outside the rejection band.

$$
\text { 10:15-10:25 (35) }
$$

Some Effects of Retinal Size and Retinal Speed on the Duration of the Spiral Aftereffect. KEVIN D. MEHLING, Postgraduate Center for Mental Health, New York, \& WILLIAM E. COLLINS \& DAVID J. SCHROEDER, Civi Aeromedical Institute, F.A.A. (read by W. E. Collins)-The duration of the spiral aftereffect and some perceptual characteristics of the stimulus situation were obtained under conditions in which visual angle was varied (a spiral of a single diameter at several distances) or was held constant (spirals of different diameters at different distances). Motor speed was constant during some sessions and varied (to make retinal speed constant) in others. Differences in results among the conditions appear due to perceptual as well as physical variables.

$$
\text { 10:25-10:35 (36) }
$$

A Dimensional Analysis of the Threshold Stimulus for Motion Discrimination. DAVID C. HENDERSON, Columbia University (sponsored by Clarence $\mathrm{H}$. Graham)-Displacement and exposure duration thresholds for movement discrimination were measured for a range of moderate-to-fast velocities and were found to reflect a trade-off relation between time and distance. Threshold energy constancy characterized the data only for combinations of low target luminance and high speed. A retinal interaction model was proposed for motion discrimination.

$$
10: 40-10: 55(37)
$$

Conflict Between Spatial and Cinetic Dimensions in Movement Aftereffect. CLAUDE BONNET, University of Paris (sponsored by Herschel W. Leibowitz)-In some conditions the surface of a test figure where one sees an aftereffect of movement does not fit with that part of the visual field corresponding to the previously stimulated retinal area. Such a result disagrees with most of what we know about aftereffects of movement. An explanation is presented which assumes this effect as resulting from an interacting process between an exteroceptive stimulation (a stationary spiral figure) and a proprioceptive stimulation consisting of the actual process of the aftereffect of movement of a partially masked moving figure.

$$
\text { 10:55-11:10 (38) }
$$

Depth Adjacency in Cue Utilization. WALTER C. GOGEL, UC, Santa Barbara-It has been found, using binocular vision, that an illusion in depth distorts the perceived depth of surrounding objects. From the present experiment the magnitude of this distortion is reduced as the depth between the illusion and the surrounding objects is increased. This result is an example of the "adjacency principle" applying to depth as well as directional separation using stereoscopic cues.

$$
11: 15-11: 25(39)
$$

Age and the Yellowness of the Crystalline Lens. STANLEY COREN, New School for Social Research, \&
JOAN S. GIRGUS, City College of CUNY-The time course of the yellowing of the crystalline lens in human Os was measured in a sample of $200 \mathrm{Os}$, ranging in age from 8 years to 79 years. Measurement was by means of color matches on highly metameric color samples.

\section{$11: 25-11: 35(40)$}

Measurement of Hue Induction. MICHAEL H. SIEGEL, Albion College-Simultaneous hue induction was studied for a series of 25 spectral wavelengths. Direction and extent of changes in hue appearance under different inducing conditions were measured using a hue estimation technique. Hue shifts depended upon the wavelength and luminance of the inducing field and their interaction with the luminance of the stimulus.

$11: 40-11: 55(41)$

Experiments on Orientation-Specific Chromatic Aftereffects. GEORGE W. MENZER, Thomas More College, \& PAUL D. JONES, University of Louisville (sponsored by $S$. C. Fulkerson)-The results of several experiments on orientation-specific chromatic aftereffects (the McCollough effect) are reported. The experiments are concerned with aftereffects produced in the presence of chromatic stimulation as well as those produced in the absence of such stimulation. A conceptual model is proposed to account for the data.

\section{PSYCHOLINGUISTICS}

$$
1: 15-1: 35(51)
$$

Reading and Spontaneous Speech in German and English: Some Comparisons. DANIEL C. O'CONNELL \& SABINE KOWAL, St. Louis University-Four groups of 40 Ss (German and American adults and children) read two passages and retold them. Variations due to language and age were noted in length and frequency of filled and unfilled pauses and in rate of speech production.

$$
1: 35-1: 50(52)
$$

Levels of Processing in Speech Perception. RUTH S. DAY \& JAMES E. CUTTING, Haskins Laboratories \& Yale University (sponsored by Alvin M. Liberman)-Some individuals are so bound by the linguistic constraints of their language that they are unable to determine the correct temporal order of speech events in a dichotic listening task. However, when the task requirements permit these Ss to bypass the linguistic level and operate solely at a psychoacoustic level, their performance improves dramatically.

\section{$1: 55-2: 10(53)$}

Sentence Comprehension: Interaction of Syntax with Knowledge about the World. KIRK H. SMITH, Bell Telephone Labs, Murray Hill, N.J.-Judging whether a complex sentence describes a possible or impossible sequence of events requires both sentence comprehension and knowledge about the world. Errors and reaction times in this task are lower when the subordinate clause describes a special class of events. Syntactic structure alone and meaning alone have little effect.

$$
2: 10-2: 30(54)
$$

The Rhythmic Structure of Speech, Music, and Other Meaningful Sounds. JAMES G. MARTIN, University of Maryland-Some rules for integrating accent and duration in temporal patterns are used to describe or predict (1) conventional musical cadences, (2) old and new data on the perceptual organization of auditory sequences, and (3) the stress pattern of English words and sentences as characterized by the output of the transformational stress cycle.

$$
2: 35-2: 45(55)
$$

Rhythmic Patterning in the Perception of Sentences. D. JAMES DOOLING, Kent State University (sponsored by Roy Lachman)-If $S$ listens to sentences in noise, his performance is enhanced if all have the same surface structure. But if the patterns of stress and syllabication are varied within the same ser.tence frame, the surface structure 
effect is greatly attenuated. Rhythmic patterning may underlie some effects at tributed to grammatical rules.

$$
2: 45-2: 55(56)
$$

Semantic Satiation of Sentences. SAM GLUCKSBERG \& PAUL BASESHORE, Princeton University-Since repetition of single words produces loss of meaning, would repetition of sentences also produce loss of meaning? We found that sentences do lose meaning after overt repetitions as indicated by both word-association data and phenomenological reports. The results point up a disparity between psychological and formal linguistic descriptions of how sentences are organized.

$$
3: 00-3: 20(57)
$$

Strategies in the Communication of Meaning. RUSSELL FOOTE, University of Wyoming (sponsored by Michael Johnson )-Twenty-four words representing different combinations of form class and frequency were used as stimuli with 25 pairs of Ss whose members were in aural contact only in a task that required a pair member to communicate stimulus words to his partner by giving generally unrestricted, verbal cues. Differences were found in the difficulty of communicating different form classes and frequencies, and a wide variety of cue strategies-some quite definitive of specific form classes-were found to be used. Results were discussed in the context of theory or research on meaning by Deese, Wittgenstein, and the General Semanticists.

\section{DECISION \& SOCIAL PROCESSES}

$$
\text { 3:45-4:00 (58) }
$$

Effects of Task Difficulty and Prior Group Support on Conformity Behavior. H. BRUCE FERGUSON, Queen's University (sponsored by Peter C. Dodwell)-A modified Crutchfield (1955) apparatus was used to present varying degrees of group support for individuals' decisions in an auditory detection task. Subsequently, conformity to unanimous and incorrect group decisions was measured. Increasing task difficulty during either support or conformity phase of the experiment resulted in higher rates of conforming, while the level of prior group support produced no differences. Questionnaire data suggest that the individual's confidence in his decision is the mediating process linking situational variables and conformity behavior.

$$
4: 00-4: 15(59)
$$

The Effect of Sequential Variables on Performance Using Attitudinal Stimuli. JOHN LAMBERTH, University of Oklahoma (sponsored by Donn Byrne)-Interpersonal attraction has often been viewed in reinforcement terms. The present investigation was undertaken to investigate the effects of variables of importance in animal learning upon performance when attitudinal stimuli and human Ss were used. Variables of interest to sequential theory, frustration theory, and dissonance theory were investigated. Ss were presented with either long or short N-lengths (the number of consecutive nonrewarded trials followed by a rewarded trial). The long $\mathrm{N}$-length group proved to be more resistant to extinction than the short $\mathrm{N}$-length group, but the significance level was marginal for a timed measure of extinction, while it was highly significant for a verbal report measure of extinction. Two additional groups were run, one being continuously reinforced (RR) and the other receiving $50 \%$ reinforcement, but with all of its nonrewarded trials preceding its reinforced trials (NR). Group NR was more resistant to extinction than Group RR. The results were most adequately explained by sequential theory.

$$
4: 20-4: 30(60)
$$

Spatial Invasion as a Function of Age and Sex. ANN M. FRY \& FRANK N. WILLIS, University of Missouri-Kansas City (read by Frank N. Willis)-This study determined the age at which a child received an unfavorable reaction when he invaded the personal space of an adult in a public place and the influence of sex on this reaction. Results indicated that unfavorable reactions appear at age 10 and that sex had little effect.

$$
4: 30-4: 40(61)
$$

Perception of Response Alternatives in an Experimental Game. THOMAS A. BARANOWSKI \& DAVID A. SUMMERS, University of Kansas-This experiment found that (1) S's perceptions of the response alternatives in a prisoner's dilemma game were often discrepant from what is assumed by game researchers, (2) S's perceptions of the response alteriatives were influenced by the conditions under which the game was played, (3) S's game behavior was related to perceptions of the response alternatives, and (4) a pattern of mutual responding, which is not treated as "cooperative" by the game theorists, was frequently perceived by $S$ as "cooperative."

$$
\text { 4:45-5:00 (62) }
$$

Believability of Information as a Function of its Logical and Affective Redundancy. RICHARD HESLIN \& JAMES ROTTON, Purdue University, \& BRIAN BLAKE, St. John's University -Seventy-two undergraduates judged the believability of descriptions of fictitious countries. When the descriptions of the countries were affectively redundant (all pieces of information equally favorable or unfavorable), there was an inverted U-shaped curve of believability as a function of logical redundancy (subjective joint probability of occurrence).

\section{HEARING AND LOWER SFNSF.S}

$$
\text { 1:00-1:10(91) }
$$

Binaural Detection of a Low-Frequency Signal as a Function of Noise Level and Interaural Noise Correlation. W. A. WILBANKS, University of Georgia-Binaural-masked thresholds for a $150-\mathrm{Hz}$ signal are shown to be a function of the interaural correlation and spectrum level of the noise. With a $+49-\mathrm{dB}$ noise, the MLD diminishes as the correlation of the noise is reduced from unity. With a $+25-\mathrm{dB}$ noise, reducing the noise correlation has virtually no effect upon detection.

\section{$1: 10-1.30(92)$}

Auditory Mach Bands. EDWARD CARTERETTE, UCLA-Experimental evidence for the existence of auditory mach bands has been obtained. Findings will be related to a theoretical model based on inhibitory neural nets.

$$
1: 35-1: 55(93)
$$

Pitch as a Medium: A New Approach to Psychophysical Scaling. FRED ATTNEAVE, University of Oregon, \& RICHARD $K$. OLSON, University of Colorado-In two experiments, transposition of sequential pure tone patterns was used as a method for scaling pitch. Those results that were scalable imply a log frequency or musical scale, not a mel scale. A sharp break occurs at about $5,000 \mathrm{~Hz}$; transposition at higher frequencies is erratic.

$$
1: 55-2: 10(94)
$$

Reciprocity Between Area and Intensity in the Warmth Sense: Data and Theories. LAWRENCE E. MARKS, John B. Pierce Foundation Lab \& Yale School of Medicine-Reciprocity between level of irradiance and areal extent is virtually complete at the warmth threshold. Spatial summation diminishes as level of warm th increases. These results are evaluated in terms of two possible models: The first assumes an interaction between summation and inhibition; the second assumes that two mechanisms mediate warmth.

$$
2: 15-2: 30(95)
$$

Reciprocity Between Area and Intensity in the Warmth Sense: A Reaction Time Study. WILLIAM P. BANKS, Pomona College, \& JOSEPH C. STEVENS, John B. Pierce Foundation Lab-The time required to respond to the presence of radiant energy applied to the forehead was measured as size and intensity of the stimulus were varied. Reaction time decreased with increases in either area or intensity. The results show a trading relationship between 
intensity and area and indicate areal summation by which an increase in area can compensate for an approximately proportional decrease in intensity and produce an unchanged reaction time.

$$
2: 30-2: 45(96)
$$

Taste and Water Taste of 26 Compounds for Man. DONALD H. McBURNEY \& THOMAS R. SHICK, University of Pittsburgh-Taste profiles of 26 compounds were obtained after adaptation to distilled water and also for distilled water after adaptation to each of the 26 compounds. Each of the "four basic tastes" is induced in water by adaptation to certain of the compounds. Those compounds having similar tastes do not necessarily induce the same intensity or quality of water taste. The results imply a peripheral locus of the water taste mechanism(s).

\section{PSYCHOPHYSICS}

$$
3: 15-3: 35(97)
$$

Futility of Hedonic Appraisals Without an Established Convention. JAMES W. JOHNSTON, JR., Georgetown University, \& EUGENE P. RUBACKY, Eye Research Foundation of Bethesda, Md.-A method is proposed for processing hedonic appraisal data as a convention. Focus on one or more sensory modalities, singly or in combination-directly or indirectly-(crossmodality matching) is not impinged. Judgments of category and ratio rating scales, magnitude estimation, and ratio range methods are compatible with the proposed technique which readily measures hedonic impact for either stimuli or questions (related to stimuli).

$$
\text { 3:35-3:45 (98) }
$$

Comparative Judgment Scale Values from Minimized Variance of Difference Dispersions. W. A. GIBSON, Queens College of CUNY-Recently it was shown that the standard Comparative Judgment Case $\mathrm{V}$ solution applies only one constraint per stimulus but is biased in fitting the data. An unbiased solution with but one constraint evolves from minimizing the variance of the difference distribution standard deviations. The normal equations are a homogeneous linear system in the unknown scale values, with complex aggregates of normal deviate reciprocals as symmetric coefficients. Implied difference distribution variances may then be analyzed nonuniquely by the cosine law into discriminal dispersions and correlations whose form and values depend on where the origin is placed in the implied space.

$$
\text { 3:50-4:05 (99) }
$$

Use of the Stone-Coles Method of Multidimensional Similarity Analysis to Explore Color Vision Dimensionality. LeROY A. STONE \& GARY J. COLES, The University of North Dakota-A new and improved similarity-analysis multidimensional scaling method was used to reanalyze judgmental data from two investigations which involved stimuli (colored lights) that had color hue differences. The multidimensional scaling results resembled the fundamental curves specified by an opponent-process theory of color vision.

$$
\text { 4:05-4:20 (100) }
$$

A Model to Derive Stimulus Scale Values from Paired Comparison Decision Times. JOAN GAY SNODGRASS, New York University-Paired comparison decision times were obtained for preference and complexity judgments of computer-generated matrix patterns. Predictions from a model which assumes that decision time is inversely related to S-stimulus distance were met by one set of complexity-judgment times, and they were used to derive stimulus scale values.

$$
4: 25-4: 40(101)
$$

Size-Weight Mlusion in Relation to Scales of Apparent Heaviness. JOSEPH C. STEVENS, John B. Pierce Foundation Lab \& Yale University, \& LEE L. RUBIN, Cornell University-Apparent heaviness of 40 objects was scaled by magnitude estimation. For any constant volume, heaviness turned out to grow as a power function of weight; the larger the volume, the larger the exponent. For any constant weight, heaviness decreased approximately as the logarithm of volume.

$$
4: 40-4: 55 \text { (102) }
$$

An Investigation of the Independence Among Individual Binary Responses in a Sequence. ALBERT S. RODW AN \& PHILIP J. HUBEK, De Paul University (read by Philip J. Hubek - The study concerned the question of whether Ss can generate a random binary sequence. The $S$, as $E$, hid a coin in either hand and presented them to an $E$ who wrote down his guesses. The $S$ received no information as to E's guesses. The sole determiner of the $S$ 's responses was himself. The criterion measure was the number of runs. Of $60 \mathrm{Ss}, 31$ responded randomly, 26 responded with significantly more runs, and 3 responded with significantly fewer runs. These results do not conform to what would be predicted from the literature. Some reasons for this discrepancy are discussed.

\section{ATTENTION \& VIGILANCE}

$$
\text { 1:15-1:25 (103) }
$$

Pupillary Activity During a Same/Different Reaction Time Task. RICHARD L. TAYLOR, Memorial University of Newfoundland-Pupil area was sampled photographically at $100-\mathrm{msec}$ intervals while Ss were making same/different reaction time judgments of letter names. Small, but systematic and very rapid, pupil changes were observed prior to leverpressing. The pattern of findings from two experiments suggests that variability in reaction time performance and in pupillary activity may be correlated indicators of loading priority in attention.

$$
1: 25-1: 40(104)
$$

Evidence of Both Perceptual Filtering and Response Suppression for Rejected Messages in Selective Attention. ANTHONY G. GREENWALD, Ohio State University-Presentation of an auditory digit typically delays RT for naming a simultaneous visual digit, but not when the auditory distractor has been repeated several times. Observation of RT to selected visual-stimulus/auditory-distractor combinations following this habituation indicated both limitation of perception of and response to the repeated auditory digit.

$$
\text { 1:45-2:00 (105) }
$$

Metered Memory Search and Concurrent Chanting. ROBERT J. WEBER \& JIM D. BLAGOWSKY, Oklahoma State University-Performance on two verbal tasks, metered memory search and emmissive chanting, was investigated for each task done separately and for the tasks done concurrently. The concurrent performance of such tasks involves "divided" verbal attention of a productive nature. For somtreatments the search rate under concurrent conditions was about the same as for metered memory search done alone (about six letters/second, similar to implicit speech rates). Arguments are made for the existence of an abstract verbal trace system that is distinct from acoustic, kinesthetic, or visual representations. 2:00-2:15 (106)

Eye Movements and Watchkeeping: I. Conspicuous Signals; II. Predictable Events. MICHEL LOEB \& JOSEPH VAN LOO, University of Louisville-In successive experiments Ss detected conspicuous signals (light onsets) varying in spatial position and inconspicuous signals (longer apparent movements) with stimulus events occurring in predictable sequence. In Experiment 1, performancy was independent of eye position, and in Experiment 2 eye position was determined largelv bv stimulus position. 2:20-2:30 (107)

Peripheral and Foveal Detection is Determined by Pattern Redundancy, DAVID C. EDWARDS \& JAMES R. ANTES, Iowa State University--Detection in the visual periphery was found to be superior for stimuli of greater redundancy. Garner's five-dot patterns and other figures 
were presented briefly at visual angles of up to $30 \mathrm{deg}$. Stimulus redundancy also lowered foveal recognition thresholds (duration), but the effect of redundancy was larger at increasingly more peripheral locations.

$$
2: 30-2: 45 \text { (108) }
$$

Remembering Visual Detail Depends on Informativeness. N. H. MACKWORTH, Stanford University-Normal adults were shown a picture and then an enlarged detail from it. They were asked to state the location of this detail in the picture from memory. The tenfold range of decision times for different pictures $(0.5-5 \mathrm{sec})$ was related to the informativeness of the stimuli, indicating that engram scanning guides visual scanning.

\section{PERFORMANCE}

$$
\text { 3:00-3:20 (109) }
$$

Effects of Intersensory Stimulation. IRA $H$. BERNSTEIN, University of Texas at Arlington-Reaction time (RT) to a combined visual-auditory event is more rapid than $\mathrm{RT}$ to the visual component alone. Several distinct effects are described that are derived from this paradigm: (1) preparation enhancement (an increase in tendency to react), (2) energy integration (an increase in effective stimulus intensity), and (3) synaesthetic interaction (an enhancement of RT by synaesthetically related visual-auditory pairings).

\section{$3: 20-3: 30(110)$}

Stimulus Discriminability and S-R Compatibility: Evidence for Independent Effects in Choice Reaction Time. IRVING BIEDERMAN, SUNY at Buffalo, \& ROBERT KAPLAN, Bell Telephone Labs, Piscataway, N.J.-In contrast to flexible capacity theories of information processing behavior, discrete stage models generally assume that the functioning of one stage (e.g., stimulus discrimination) proceeds independently of the demands on some other stage (e.g., response selection). These alternatives were tested by factorially varying stimulus similarity and S-R compatability in a speeded brightness discrimination task. The independent stage hypothesis was supported by the finding that the experimental variables did not have interactive effects on the means and higher-order moments of the RT distributions.

$$
3: 35-3: 45 \text { (111) }
$$

A Comparison of Simple Reaction Time to Psychophysically Matched Auditory and Visual Response Signals. DAVID L. KOHFELD, Southern Illinois University at Edwardsville-Simple auditory and simple visual RT was compared on the same scale by presenting psychophysically matched response signals having intensities of $30 \mathrm{~dB}$ $(.0001 \mathrm{~mL}), 60 \mathrm{~dB}(.10 \mathrm{~mL})$, and $90 \mathrm{~dB}(100 \mathrm{~mL})$. Mean $\mathrm{RT}$ for both auditory and visual signals at 90 and $60 \mathrm{~dB}$ was the same; for the 30-dB comparison, RT was longer for the visual than for the auditory signal. In view of these results, the common assumption that auditory RT is shorter than visual $R T$ was reconsidered.

$$
\text { 3:45-4:00 (112) }
$$

The Speed-Accuracy Trade-Off Function as a Measure of Information Processing. JOSEPH S. LAPPIN \& KENNETH DISCH, Vanderbilt University-Choice RT experiments were designed and analyzed to answer the following questions: (1) Is some speed-accuracy trade-off invariant with fluctuations in the distribution of RTs and error rates? (2) What measure of accuracy is linearly related to RT? (3) How is the trade-off function affected by demands of the discrimination task?

$$
\text { 4:05-4:20 (113) }
$$

Sustained Performance During Forty-Eight Hours of Continuous Work. BEN B. MORGAN, JR., \& EARL A. ALLUISI, University of Louisville-The synthetic-work approach to performance assessment was employed on a multiple-task performance battery during a $48-\mathrm{h}$ period of continuous work. Results indicated that after $40 \mathrm{~h}$ of work, average crew performance had reached a maximum decrement approximately $35 \%$ below normal levels of output. Complete recovery was attained following $24 \mathrm{~h}$ of rest and recovery. These results are compared to those of previous sleep-loss studies.

$$
4: 20-4: 35 \text { (114) }
$$

Approach-Set as an Explanation of Warm-Up Decrement. RICHARD A. SCHMIDT, University of Michigan, \& JACQUES NACSON, Columbia University-An interpretation of the set hypothesis for warm-up decrement (WU) was proposed and the prediction tested in three separate experiments. The hypothesis predicts that if WU is due to the loss of "approach" over rest, engaging in an appropriate "approach"-reinstating activity just prior to postrest performance should result in a decrease in WU. Findings showed that Ss performed significantly better on initial recall immediately after having practiced on the "approach"-reinstating task than if no such activity preceded the trial.

$$
4: 40-4: 55(115)
$$

Set Differentiation in Short-Term Memory. STEPHEN REDER, Rockefeller University, \& ROBERT A. BJORK, University of Michigan (sponsored by Daniel J. Weintraub)-Short-term memory tasks admit a variety of search and retrieval schemes, the relative efficiency of which depends heavily on the processes by which item sets are discriminated in memory. This paper reports several recognition-search experiments involving explicit judgments of set membership. The results suggest a need for reinterpretation of standard recognition-search experiments.

$$
\text { 4:55-5:05 (116) }
$$

Recognition Memory: Successive Probes of a Memory Store. KEITH G. SCOTT, University of Dlinois-Retarded children were presented with 3,5 , or 9 pictures exposed for 2 sec each from a pool in a procedure similar to that used by Sternberg. This was followed by three successive probes including all possible orders of positive and negative. The process of probing the store did not produce the massive interference found with briefer presentations by Sperling. $5: 10-5: 25$ (116A)

Reduction in psychological refractoriness with practice. ROBERT GOTTSDANKER, UC, Santa Barbara-After extended practice on a successive choice reaction task with a constant intersignal interval of $100 \mathrm{msec}$, an $\mathrm{S}$ lowered both RTs markedly, until $\mathrm{RT}_{2}$ was elevated by less than 25 msec, with $R T_{1}$ perhaps not elevated at all. When $S$ was shifted to variable intersignal intervals, he showed both positive and negative transfer effects. While some psychological refractoriness appears unavoidable, performance on the dual task exhibits characteristics typical of a learned skill.

\section{MENiORY}

$$
9: 15-9: 30(117)
$$

The Role of Rehearsal Strategy in Serial-Probed Recall. STEPHEN E. PALMER \& PETER A. ORNSTEIN, Princeton University (sponsored by Carl E. Sherrick, read by Peter $A$. Ornstein)-In a serial-probed recall task, the serial position curve for Ss rehearsing items as paired associates showed no primacy effect, while that for Ss rehearsing cumulatively was pronounced. This large primacy effect was partly due to a transfer of information from primary to secondary memory.

$$
9: 30-9: 40(118)
$$

The Retrieval of Words from Superordinate and Subordinate Categories. ELIZABETH F. LOFTUS, New School for Social Research, JONATHAN L. FREEDMAN, Columbia University, \& GEOFFREY R. LOFTUS, Stanford University (sponsored by John W. Senders)-The purpose of the experiment was to distinguish between two models of semantic organization. The results support a model in which each word is the patriarch of its own hierarchy as opposed to a predetermined hierarchical model in which a 
search begins at the top of the hierarchy and moves downward.

\section{$9: 45-9: 55$ (119)}

Overt Motor Rehearsal in Kinesthetic Recall. GEORGE E. STELMACH, UC, Santa Barbara-Short-term kinesthetic retention was measured under immediate recall, overt motor rehearsal, and rest conditions. Forgetting occurred along the dimension of movement extent. Overt motor rehearsal was found to substantially shift recall errors in a positive direction and caused increases in variable error. 9:55-10:05 (120)

Retention of the Position of a Single Joint as the Unit of Analysis of Motor Memory. BRUNO PREILOWSKI, Tulane University (sponsored by Ina $\mathrm{McD}$. Bilodeau)-Recall norms (error scores) for separate elbow and shoulder movements in the horizontal plane were used to predict reproduction of movements involving simultaneous, independent rotation at the same two joints in the same plane. Rank-order comparison of empirical data with a multiplicative combination of norms vielded an $r_{\mathrm{c}}$ of .92 .

$$
\text { 10:30-10:45 (121) }
$$

Strolling Down Memory Lane with the Method of Locations. EUGENE WINOGRAD, MICHAEL KARCHMER, \& RICHARD TUCKER, Emory University-Some data obtained with an experimental analogue of the method of locations, an ancient mnemonic system, will be reported. A photographed "walk" through the university cafeteria served as the locations. Although the method proved a powerful learning system, retroactive inhibition was found following multiple learning. A large cueing effect was found as well.

$$
\text { 10:45-11:00 (122) }
$$

Effect of Spacing on Recognition Accuracy and Latency. EDWIN MARTIN \& ARTHUR W. MELTON, University of Michigan-In the Shepard-Teghtsoonian paradigm, recognition accuracy and latency are linearly related. Longer $P_{1}-P_{2}$ intervals facilitate recognition on the third presentation $\left(P_{3}\right)$. Recognition on $P_{3}$ is identical to recognition on $P_{2}$ when $S$ said "new" on prior presentations. Initial false positives facilitate recognition and shorten latencies.

$$
\text { 11:05-11:25 (123) }
$$

Parallel Processes in Word-Recognition. DAVID E MEYER \& GWEN B. ELLIS, Bell Telephone Labs, Murray Hill, N.J. (sponsored by Peter D. Bricker)-Ss made separate decisions as to whether strings of letters (1) were words and (2) denoted instances of specified semantic categories. Reaction times varied directly with category size, but the effect was significantly larger for words than for nonwords. These and other results together suggest a parallel "race" between retrieval processes that ascertain a string's word status and its meaning.

$$
11: 25-11: 45(124)
$$

The Effects of Response Formal Similarity on Paired-Associate Transfer and Retroactive Inhibition. JAMES W. PELLEGRINO \& WILLIAM F. BATTIG, University of Colorado-Orthogonal manipulation of intralist response formal similarity (high and low) within the two lists for $A-B, A-C$ and $A-B, C-D$ paradigms showed maximal retention of high-similarity first-list responses, especially when second-list response similarity was low. Retention was poorest for low first lists followed by high second lists.

\section{HUMAN LEARNING}

$$
8: 45-8: 55(125)
$$

Speed and Accuracy in Rotary Pursuit Tracking. HENRY S. ROSENQUIST, University of Akron-Ss tracked a rotary pursuit device whose speed, initially set at $20 \mathrm{rpm}$, progressively increased so long as certain accuracy levels were maintained. When tested later on a criterion speed of $60 \mathrm{rpm}$, they performed no better than control Ss who had trained at 60 rpm from the start.
$8: 55-9: 10(126)$

A Theory of Psychomotor Skill: Derivation and Data. CLYDE E. NOBLE, University of Georgia-Consistent with principles of process, time, continuity, and reinforcement, assume basic formula is $\mathrm{R}=\mathrm{MH}+\mathrm{T}$, where $\mathrm{R}=$ response score, $\mathrm{T}=$ transfer constant, $\mathrm{M}=$ maximum $\mathrm{R}$ when $\mathrm{T}=0$, $\mathrm{H}=$ habit strength. Postulating that reaction tendency is continuous $f(x)$ rather than discrete $f(N)$, let $g(x)=a-f(x)$, where $a=$ reaction asymptote. From derivatives $f^{\prime}(x)=k g(x)$ and $g^{\prime}(x)=-f^{\prime}(x)$, integration gives $g(x)=c e^{-k x}$. Since $f(x)=a-g(x), f(x)=a-c e^{-k x}$. Substituting $a=c+T$ and $c=M$ yields rational equation $R_{n}=M\left(1-e^{-k N}\right)+T$. Data from 10 different psychomotor tasks agree with deduction. Experimental and human-factor parameters are coordinated to theory, with over $99 \%$ of variance in $\mathrm{R}$ predicted by exponential law.

$$
9: 15-9: 25 \text { (127) }
$$

Enrichment of Supplementary Feedback Stimuli. R B. PAYNE \& C. W. ARTLEY, University of Georgia-New data confirm an earlier report on the investment of otherwise inert supplementary feedback stimuli with the capacity to regulate psychomotor performance. In addition, partially complete results suggest that this capacity is a negatively accelerated increasing function of enrichment trials.

\section{$9: 25-9: 40(128)$}

Remembering Location of Information in Text. ERNST Z. ROTHKOPF, Bell Telephone Labs-After reading a 3,000 -word text, $\mathrm{Ss}(\mathrm{N}=53)$ were asked to recall (1) substantive information and (2) where this information was located in the passage. Memory for locations in the text sequence and also within any page were substantially more accurate than chance. Accuracy of substance and location recall were correlated.

\section{0:00-10:15 (129)}

Markov Models of Verbal Discrimination Learning. JAMES R. ULLRICH, University of Montana-Ss were given a verbal discrimination task in which the number of alternatives, the meaningfulness of the alternatives, and the grouping conditions were varied factorially. Grouping condition refers to similar or different pairings of correct and incorrect alternatives on successive trials. The results were analyzed in terms of Markovian learning models and in terms of frequency theory.

$$
\text { 10:15-10:35 (130) }
$$

Anxiety, Drive Theory, and Computer-Assisted Learning. C. D. SPIELBERGER, H. F. O'NEIL, \& D. N. HANSEN, Florida State University-The effects of anxiety on computer-assisted learning were investigated in four studies in which high school and college Ss were presented with science and mathematics materials by an IBM 1500 CAI system. The findings will be discussed in terms of their implications for Spence-Taylor drive theory and Spielberger's trait-state anxiety theory.

$$
\text { 10:40-10:50 (131) }
$$

Dimensional Dominance in Normal Preschool Children. JOAN F. GUSINOW \& LOUIS E. PRICE, University of New Mexico-Form and color preferences of 96 preschool Ss were assessed using a matching task. In a discrete-trial discrimination-learning task, one group was differentially reinforced and another group was additionally instructed to verbalize the class name of their nondominant dimension. Dimensional dominance was shown to be a modifiable response and a bias which influences performance.

$$
\text { 10:50-11:00 (132) }
$$

The Effects of Average Degree of Polarization on Serial Learning and the von Restorff Effect. RICHARD A. KASSCHAU, University of South Carolina-In two separate experiments the average degree of polarization $\left(\mathrm{D}_{4}\right)$ on the semantic differential of words composing a list was varied, holding associative meaningfulness (m) constant. In both experiments $\mathrm{D}_{4}$ and number of trials to criterion were significantly positively related. Effects previously 
demonstrated varying $m$ were essentially replicated varying $\mathrm{D}_{4}$

$11: 05-11: 15(133)$

Reversal of Correctness on Alternate Trials of a Verbal Discrimination List. MARIAN SCHWARTZ, University of Wisconsin, Madison-A verbal discrimination list was presented for 24 study trials, each followed by a test trial. For all 12 pairs, correctness was alternated on succeeding study trials. Performance first declined, then improved as Ss learned which words were correct on common trials. Significant variables were sex of $\mathbf{S}$ and grammatical class, but not intrapair relatedness.

\section{$11: 20-11: 30(134)$}

Immediate vs Delayed Punishment in Humans. W. $H$. TEDFORD, JR., \& REAGAN ANDREWS, Southern Methodist University-Ninety student volunteers chose between immediate or delayed shock when shock was delivered on $100 \%, 90 \%, 75 \%, 50 \%$, or $25 \%$ reinforcement schedules. Results verified the hypothesis that Ss choose immediate punishment when it is certain to occur but tend toward delayed punishment as the situation becomes ambiguous.

\section{FORM PERCEPTION}

$$
\text { 8:45-9:00 (141) }
$$

Mood as it Manifests Itself in Perceptual Behavior. STEPHEN JAY SEEMAN \& ROBERT H. POLLACK, University of Georgia-Sixty Ss, 30 high in moodiness, 30 low, divided equally by sex, were compared on form detection and backward masking. Depression scores were obtained before and after each task. Results showed no effect of moodiness, but extreme states of euphoria and depression raised masking thresholds. Sex differences were also demonstrated.

$$
\text { 9:00-9:15 (142) }
$$

An Effect of Meaning on the Visual Perception of a Contour. RONALD M. PICKETT, ROBERT A. FIRGER, \& DAVID L. LOISELLE, Harvard School of Public Health-We report an effect of varying the meaning of a contour on ability to distinguish slight variations in its shape. In one condition 50 Os were set to see the contour as the silhouette of an object. In the other condition $50 \mathrm{Os}$ were set to see the contour as an abstract design. Results are expressed in terms of signal detection theory.

$$
9: 20-9: 30(143)
$$

Intersensory Transfer of Temporal Patterns. LEO RUBINSTEIN \& ERNEST GRUENBERG, Columbia University-Temporal pattern perception for vision and audition was measured using pair comparisons of precisely determined rhythms. Visual rhythms were more difficult to match than comparable auditory ones. The difference between crossmodal and intramodal transfer may be related to the frequency of pattern elements, crossmodal performance dropping more when frequency rose. Symmetry or "goodness" influences the processing of the first pattern more than it does the second pattern in the pair comparison.

\section{9:30-9:45 (144)}

General and Specific Factors in the Intersensory Transfer of Form. JEFFREY L. CLARK, JOEL S. WARM, \& DONALD A. SCHUMSKY, University of Cincinnati-This study was designed to determine if nonspecific factors could account for crossmodal transfer of paired-associate learning between vision and touch. Visual metric figures and their tactual analogues served as stimuli and familier adjectives as responses. Positive crossmodal transfer effects characterized by a lack of directionality were obtained. Intersensory transfer was not accounted for on the basis of nonspecific learning factors.

$$
9: 50-10: 05(145)
$$

Systematic Imposition of Bias in the Perception of Similarity: Distortion Through Class Structure. LEONA S. AIKEN, Temple University, RICHARD M. FENKER, Texas
Christian University, \& DONALD R. BROWN, Purdue University-This study evaluates the influence of one type of distributional constraint, class structure, on the perceived distance between patterns embedded in a multidimensional feature space. Perceived similarity of between-class pattern pairs was shown to be a function of the estimated distance of the pair members from the class centroids.

$$
\text { 10:05-10:20 (146) }
$$

Structure Issues in Pattern Recognition and their Relation to Template Matching and Feature Testing Models. JAMES T. TOWNSEND, Purdue University (sponsored by Donald Brown)-Five structure dichotomies are suggested as providing fundamental information about pattern recognition viewed in information-processing terms. These are related to the familiar but often vague template-matching vs feature-testing hypotheses and to hierarchical and nonhierarchical decision processes. It is also shown that investigation of identifiability properties of these dichotomies can elucidate their behavioral implications as well as their mutual testability.

$$
\text { 10:40-10:50 (147) }
$$

Multidimensional Scaling Solutions as Models for Memory Representation. D. W. HASTINGS, R. M. FENKER, S. H. EVANS, Texas Christian University-Differential sets of circles, varying in brightness and area, were employed in a three-group experimental design to test multidimensional scaling solutions as a model for memory representations of stimuli. Results confirmed expected differences between experimental groups, while suggesting that the traditional distance measures used in scaling techniques are inappropriate.

$$
\text { 10:50-11:00 (148) }
$$

Pattern Encoding: The Effects of Cluster Separation and Interstimulus Interval on Visual Pattern Recognition. MARGARET A. HASTINGS, DONALD F. DANSEREAU, \& MALCOLM D. ARNOULT, Texas Christian University-The effects of cluster distance and interstimulus interval upon classification, scaling, and selection of schematic patterns were investigated. Interstimulus interval had differential effects upon performance, while abstraction of pattern information was demonstrated under all conditions without Ss receiving knowledge of results.

$$
\text { 11:05-11:20 (149) }
$$

Form Perception as a Function of Histoform Complexity and Problem Homogeneity. JOHN D. REPKO \& JOHN B. THURMOND, University of Louisville-Twenty $\mathrm{Ss}$ in each of six exposure-time conditions were required to identify the correct figure from a display of metric histoforms. The perimeter of histoforms was used as a measure for determining the homogeneity (or heterogeneity) of stimulus problems. Both speed and accuracy indicated that perceptual performance increased as a function of exposure time and was in all cases higher for heterogeneous problems, but important differences in performance were observed as a function of the perimeter and histoform complexity.

$$
11: 20-11: 35(150)
$$

Discrimination of VARGUS-7 Histoforms as a Function of Prototype Familiarization and Task Memory Requirements. THOMAS J. REBBIN \& BILL R. BROWN, University of Louisville (sponsored by James $N$. Cronholm - Following extensive familiarization with three population prototypes in a same-different classification task, Ss made simultaneous or sequential same-different classifications of VARGUS-7 histoforms which were distortions of these same prototypes. Contrary to the predictions of the prototype-encoding model, prototype training did not facilitate performance in comparison to control groups, nor did it reduce performance differences due to different task memory requirements (simultaneous vs sequential conditions). 
$11: 40-11: 55(151)$

Fragmentation and Grouping in Rotating Figure llusions. BARBARA GILLAM LAWERGREN, Columbia Iniversity-Certain wire figures were observed to fragment luring rotation on a vertical axis, with their parts ipparently rotating in opposite directions some of the time. This phenomenon was used as a technique to measure the srouping of lines with respect to apparent depth. Grouping lecreased with an increase in the difference in line srientation, and for fixed orientations, with an increase in ine separation.

\section{ECALL}

$$
1: 15-1: 30(176)
$$

Free-Recall Learning of Words in Variable Intratrial Context. ENDEL TULVING, Yale University-Effects of repetition, such as increments in recall, in multitrial memory tasks have practically always been studied under conditions where repetition of each item is confounded with the repetition of its intratrial context. In this paper I discuss theoretical implications of results from experiments in which the two kinds of repetition are analytically separated.

\section{$1: 30-1: 40(177)$}

Free-Recall of Spatial Orientational Information of Visual Figures. FRED L. ROYER, Brecksville V.A. Hospital-Equivalence sets are figures identical under operations of 90-deg rotation and reflection. Free recall learning of lists of figures is influenced by the number of members of the set, as well as set size. Rotation errors (listing unused members of a set) are similarly influenced. Figure information seems more durable in memory than spatial orientational information.

$$
1: 45-2: 00(178)
$$

Recalling Recent Exemplars of a Category. JAMES L. FOZARD, Boston V.A. Outpatient Clinic \& Harvard Medical School, JUDITH MYERS, Simmons College, \& NANCY C. WAUGH, Harvard Medical School-In a sequence of names of animals, cities, etc., Ss were instructed to remember only the two most recently presented names in each of four categories. $S$ recalled either both items (no cue) or only one item (earlier cued by later and vice versa). A hypothesis that order and item information are independent was rejected.

$$
\text { 2:00-2:15 (179) }
$$

Generative Strategies in Retrieval? GEORGE MANDLER \& KARALYN E. PATTERSON, UC, San Diego-High-probability and low-probability instances of categories (as defined by norms) show essentially no difference in recall (when Thorndike-Lorge frequency is controlled). A categorized list generated by $\mathrm{Ss}$ is better reproduced under recall instructions than regenerate instructions. Recall of categorized lists does not depend primarily on category generation.

$$
\text { 2:20-2:35 (180) }
$$

Priority Effects in Free Recall. SAM C. BROWN \& CHARLES P. THOMPSON, Kansas State University-Do Ss recall first items with low or high response strength? Neither is the case. Ss recall items of moderate strength first and items of high and low strength later. This curvilinear relationship suggests a minimal interference strategy in which availability and degree of learning conjointly determine order of recall.

$$
2: 35-2: 50(181)
$$

Organization and Reorganization in Free-Recall Learning. JOHN A. ROBINSON \& TIMOTHY HIGGINBOTHAM, University of Louisville-Two free-recall learning experiments using Bower's imaging method were performed. Experiment 1 replicated the disruptive effect of changing subjective units but failed to replicate the facilitative effect of compounding smaller units into larger ones. Experiment 2 explored the locus of the disruptive effect by varying the encoding and rehearsal components of the task. The results indicate that when $S$ is given sufficient time to encode to a subjective criterion of stability the effect of changing units is eliminated. Rehearsal had no differential effect on recalls.

$$
\text { 3:10-3:25 (182) }
$$

Learning to Retrieve in Free Recall: Comparative Data. MICHAEL COLE, Rockefeller University-A clusterable list of common nouns was presented for five trials of free recall. Various cuing procedures and constraints on recall were introduced for different groups of African and American children. Results indicate that recall deficits can be attributed in part to retrieval failures an;that retrieval "habits" can be quickly learned.

$$
\text { 3:25-3:35 (183) }
$$

Facilitation of Word Recall in Young Children. CLESSEN MARTIN, Texas A\&M University, \& ERNIE ADAMS, Florida State University-This study examined the effects of association value, stimulus pretraining, and response learning among first graders learning to read individually presented sight words. The results indicated that high-association-value words were learned more rapidly than low-association-value words. Response learning facilitated performance but stimulus pretraining had no effect.

$$
3: 40-3: 55 \text { (184) }
$$

Consolidation in Paired-Associate Learning: Retrograde Amnestic Effect of Similar Items as a Function of Delay. T. K. LANDAUER, Bell Telephone Labs-One critical item was followed by a variable number of dissimilar items, then a block of similar items, then other dissimilar items, the total set kept constant. In general, critical item recall, tested $20 \mathrm{~min}$ later, varied directly with the number of dissimilar items which preceded the block of similar items. 3:55-4:05 (185)

The Total Time Hypothesis in Multitrial Free Recall. JOHN C. KOEPPEL, University of Southern Mississippi, \& LARRY D. STANLEY, Henderson State College-A mixed list of conceptually related and unrelated items was shown to separate groups of Ss at presentation times of 1,2 , or $4 \mathrm{sec}$. With total time equated at various stages of recall across groups, the total-time hypothesis was supported with related stimuli but consistently contradicted when unrelated items were analyzed.

$$
4: 10-4: 25 \text { (186) }
$$

Categorizing Ambiguous Words. ERWIN M. SEGAL, STEPHEN GOLDBERG, \& TIMOTHY E. MOORE, SUNY at Buffalo-A list containing 10 ambiguous words (e.g., crane) and 60 additional words (e.g., flamingo, bulldozer) was randomly presented to Ss. The probability of recalling the ambiguous word under one category name is a positive function of recalling it to the other name. This result is independent of the order of presentation and of recall but does not occur with blocked presentation.

\section{INFORMATION PROCESSING}

$$
1: 15-1: 25(212)
$$

Variations on a Theme of Posner: Physical and Name Codes of Heard Letters. MAX COLTHEART \& FRANCES ALLARD, University of Waterloo-Upon hearing the second of two spoken letters, Ss indicated whether the two stimuli were the same letter or not. When they were the same letter, they were sometimes physically identical (e.g., same voice) and sometimes not (e.g., different voices). Comparisons of the RT/ISI relationship in these two situations permit inferences about the characteristics of a sensory buffer in the auditory modality.

$$
1: 30-1: 45(213)
$$

The Processing of Visual Information in a Forced-Choice Search Task. JOHN E. HOLMGREN, University of Maryland-Displays containing from one to five consonants were briefly presented to Ss. They rapidly determined which of two target letters appeared in the display. Search rates were four times as slow as in the corresponding yes-no 
task. Comparison of these results with those of a subsequent three-choice study allows new inferences to be drawn concerning processing of visual information.

$$
\text { 1:45-2:00 (214) }
$$

Processing of Sensory Input Relative to a Constructed Image. SYDNEY JOELSON SEGAL, City College of CUNY, \& VINCENT FUSELLA, CUNY-Sixty-four Ss imaged three items; none noticed a supraliminal stimulus or could guess during which image it occurred. The stimulus was reprojected for half the Ss, and their guesses improved; the stimulus was described to $32 \mathrm{Ss}$, and their guessing deteriorated. Stimulus and image form one integrated construction; new stimulus information improves detection only if relevant to that construction.

$$
\text { 2:05-2:20 (215) }
$$

Independence of Successive Visual Inputs. MICHAEL E. DOHERTY \& STUART M. KEELEY, Bowling Green University-The hypothesis that successive visual stimuli are perceptually independent, rather than being increasingly clear, was tested. Ss made identification responses to tachistoscopically presented graphemes $(\mathrm{A}, \mathrm{T}, \mathrm{U})$, presented one at a time and three in succession. Many multiple trials had a discrepant letter in one of the three serial positions. Results unequivocally supported the independence hypothesis.

\section{$2: 20-2: 35(216)$}

An Addition to the Reading-Scan Hypothesis. D. R. SCHISSLER \& M. A. BARATTA, Northeastern University (sponsored by John Armington)-Letters were presented in pairs to the left or right of fixation. The stimulus letter, appearing 6 deg 36 min from fixation, was accompanied by a noise letter at either $7 \mathrm{deg} 26 \mathrm{~min}$ or $5 \mathrm{deg} 46 \mathrm{~min}$ from fixation. Reaction time and error rate showed more interference from the $7-\mathrm{deg} 26-\mathrm{min}$ noise letter than for the 5-deg 46-min noise letter for the left and right conditions. Since a reading scan cannot account for these results, an additional type of scanning is proposed.

$$
\text { 2:40-3:00 (217) }
$$

On the Processing of Simple Visual and Auditory Stimuli at Distinct Levels. DAVID LaBERGE, University of Minnesota-Three RT studies involving a Donders Type c reaction explored perceptual routes taken by colors and tones when the type of catch stimulus was varied. Two levels of processing were clearly identified from analyses of data of latency distributions and generalization gradients.

$$
3: 20-3: 35(218)
$$

Information Processing and Serial Learning. LEE W. GREGG, Carnegie-Mellon University-Analyses of serial position effects and trial-by-trial acquisition of items vs learning time for two experiments on induced chunking trace the hierarchical organization of list segments. A one-parameter model is proposed to explain these data.

$$
\text { 3:35-3:50 (219) }
$$

No Trace of the Visual Image. DENNIS H. HOLDING, University of Louisville-Information available from a visual trace may be limited to what is selected on presentation. Making partial reports of tachistoscopic letter arrays depends largely upon guessing the cue sequences. Measuring where Ss are looking shows that they can recover little else. Cue uncertainty depresses immediate and delayed reporting.

$$
\text { 3:55-4:10 (220) }
$$

The Duration of Word Meaning: Stroop Interference for Different Intervals Between Word and Color Presentations. FREDERICK N. DYER, Army Medical Research Lab-Interference to color naming fluctuated at a high level then decreased sharply as the interval between presentation of an incongruent color word and its later coloration increased from 0 to $500 \mathrm{msec}$. Facilitation of color naming by a congruent color word showed a somewhat different relationship to this word-color interval.

$$
4: 10-4: 25 \text { (221) }
$$

The Likelihood-Ratio Principle and Conjoint
Measurement. THOMAS S. WALLSTEN, University of North Carolina (sponsored by David H. Krantz)-It is often assumed that the likelihood-ratio principle describes how Ss evaluate alternatives on the basis of probabilistic information. Considering this model in terms of polynomial conjoint measurement results in strong behavioral predictions. An experiment showed $S$ s to combine the information as called for, but the psychophysical functions were biased towards the more likely alternative, while the response function led to "conservatism."

$$
4: 30-4: 50(222)
$$

Probing the Organization of Noun Lists by Inducing Modality-Specific Conflict at Output. BRIAN BYRNE \& LEE R. BROOKS, McMaster University-Depending on material and task, Ss report learning lists of concrete nouns as visualized scenes, as series of imaginally or associatively related subgroups, or as rhymed jingles. The degree of modality involvement thus suggested was corroborated by the conflict induced by vocal or visually monitored output concurrent with postcriterion recall.

\section{PAIRED-ASSOCIATE LEARNING}

$$
\text { 1:45-1:55 (223) }
$$

Subject-Controlled Optimization in Paired-Associate Learning. JOHN W. BRELSFORD, JR., Rice University-Three groups were given 240 anticipation trials on a paired-associate list. Optimization-group Ss programmed their own sequences of trials, while two control groups received yoked and randomized schedules, respectively. Groups differed reliably during training and on a 24-h retention test, with the optimization group performing best and the random group worst.

$$
\text { 1:55-2:10 (224) }
$$

Transfer of Stimulus Differentiation and Stimulus-Encoding Alternatives. HENRY C. ELLIS, University of New Mexico-Differentiation among stimuli during first-list learning produces considerable positive transfer in second-list learning under condition of high intralist-stimulus similarity, whereas the usual negative transfer occurs with low intralist-stimulus similarity. This transfer effect, due to stimulus processing, is found only with stimulus patterns containing several relevant redundant cues such as letter matrices and random shapes, and not with trigram stimuli.

$$
\text { 2:15-2:25 (225) }
$$

Presentation Rates vs Frequencies of Reinforcement (Study) and Test Trials in Paired-Associate Learning. CHIZUKO IZAWA, SUNY at Buffalo-Effects of successive $R$ (reinforcement) and $T$ (test) trials combined with exposure times and frequencies were investigated with the total acquisition times kept constant. Clear differences manifested in acquisition curves diminished in retention data. Repetitive testing of the same item in a row demonstrated progressive changes over a block of 6-sec response times.

\section{$2: 25-2: 40(226)$}

Aided and Unaided Recall of B Terms Following A-B Training. SLATER E. NEWMAN \& GEORGE W. LOGAN, North Carolina State University-Ss were given eight A-B pairing trials and were then tested for aided or unaided B-term recall. All Ss were then tested again, half receiving the same kind of test and the rest receiving the other kind. On both first and second tests, aided recall was better than unaided recall $(p<.01)$. The use of unaided B-term recall to assess B-term availability will be discussed.

$$
\text { 2:45-3:00 (227) }
$$

Recognition Latency and Meaingfulness in Paired-Associate Learning. RONALD LEY \& DAVID LOCASCIO, SUNY at Albany-In PAL, associative reaction time (time between presentation of a verbal unit and first association produced) has been shown to be a significant response-term variable independent of meaningfulness, whereas recognition latency (time between the presentation 
of a verbal unit and the pronunciation of the unit) was found to have no effect within equated levels of meaningfulness.

\section{$3: 05-3: 15(228)$}

Repetition vs Imagery Instructions in the Short- and Long-Term Retention of Picture and Word Paired Associates. A. DANIEL YARMEY \& WILLIAM J. BARKER, University of Guelph-Ss learned two PA lists, each consisting of 18 picture pairs and 18 word pairs. Half of each list was studied by repetition, the remainder by imagery. Retention was tested for both cued and noncued recall of the original study method immediately after learning and 1 week later. The results support a multiple memory-store hypothesis and a theory that imagery study is an efficient mnemonic process.

\section{CONCEPT LEARNING}

$$
3: 40-3: 50(229)
$$

Effects of Acoustic and Semantic Similarity on Concept Identification. VERONIKA VAGO, University of Guelph (sponsored by R. H. Gibson)-Since both acoustic and semantic similarity influence efficiency of memory, the role of memory in concept identification (CI) was investigated by varying the acoustic and the semantic similarity of the stimuli used in the CI task. Varying acoustic similarity had no effect on CI, but CI was significantly impaired when dimension names in a CI task were semantically similar.

$$
\text { 3:50-4:00 (230) }
$$

Behavioral and Physiological Aspects of Alcoholic vs Normal Performance in a Concept Identification Task. STEVEN M. FISHKIN \& VLADIMIR PISHKIN, V.A. Hospital \& University of Oklahoma School of Medicine, \& MONTE L. STÄHL, V.A. Hospital, Oklahoma City-Thirty-six chronic alcoholics and 36 hospitalized controls were compared on concept identification performance. No significant difference occurred in errors or trials to criterion. The groups were affected by manipulating prior experience with failure, but the usual effect of task complexity did not occur. No differences in GSR or muscle action potential were found for the groups, but they did differ in response rates.

$$
\text { 4:05-4:20 (231) }
$$

The Development of Natural Language Concepts. ELI SALTZ \& ELAINE SOLLER, Wayne State University, \& IRVING SIGEL, SUNY at Buffalo-Natural language concepts appear to be fragmented in young children. With age, integration of the fragmented subconcepts develops. The results of this study are consistent with the overdiscrimination theory proposed previously by Saltz and Sigel.

$$
4: 20-4: 35(232)
$$

Creative Aptitudes in a High-Intelligence Population. DONALD JOHNSON, Columbia University, \& MAX L. FOGEL, Eastern Pennsylvania Psychiatric Institu te (read by Max L. Fogel)-A group of highly intelligent Ss was administered a newly developed battery of difficult tests assessing creative and related cognitive aptitudes, including measures of synthesizing, verbal and figural production, symbol reasoning, memory, verbal fluency, sequencing, redefinition, evaluation, clerical skill, and spatial relations abilities. Results indicated that the diversified creative aptitudes have low intercorrelations; hence, very high levels of creativity are found infrequently even in this selective population.

$$
4: 40-4: 50(233)
$$

Characteristics Determining Anagram Difficulty. ROGER L. DOMINOWSKI, DOUGLAS M. JOHNSON, \& WENDY ROTHWELL, University of Illinois at Chicago Circle-In a multiple-regression analysis of the difficulty of 232 anagram (scrambled-word) problems, two-thirds of the variance was accounted for by a small set of predictors: Word frequency, anagram-word similarity, and the uncertainty of bigram positions in the word. A multiple-strategy model of anagram solving is suggested.

$$
\text { 4:55-5:00 (234) }
$$

(Read by title only)

Rule Learning as a Function of Rule and Length of Postfeedback Interval. GEDIMINAS NAMIKAS \& NOEL CAREY, University of Windsor-Each of 144 Ss solved one of two rule-learning problems in a study which combined four rules and three $(1-, 8-$, and 15-sec) postfeedback intervals in an orthogonal design. Visual stimuli, varying in three (two relevant + one irrelevant) tri-level dimensions, were presented in a random sequence restricted to an equal number of negative and positive instances. Rule learning was found to increase significantly in difficulty from conjunctive through inclusive disjunctive, exclusive disjunctive, and biconditional rules. The latter two are complementary; still, the biconditional rule was significantly more difficult. The range of postfeedback intervals used in the study did not produce differential performance.

\section{SHORT-TERM MEMORY}

9:00-9:10 (248)

The Influence of Retrieval Cues and Set Organization on Short-Term Recognition Memory. DONALD V. DeROSA \& CHRISTINA KAMINSKY, Bowling Green State University-A recognition-memory reaction time (RT) task examined an S's ability to retrieve information from a set of six memorized elements. The memory set was composed of letters and digits. Cues presented after the last to-be-remembered item informed $S$ of the category from which a test item was drawn. Cues which were informative reduced RTs. Also RTs increased as the size of the cued subset increased.

$$
\text { 9:10-9:25 (249) }
$$

A Cognitive Interpretation of RI Effects in STM. A. D. BADDELEY \& J. R. ECOB, University of Sussex, \& DENISE SCOTT, University of Bath (sponsored by D. A. Norman)-This study distinguishes between an interference-theory interpretation of RI effects in STM and one assuming $S$ is employing a retrieval rule. Results (1) support the retrieval-rule hypothesis, (2) show such rules may use acoustic or semantic similarity, whereas (3) negative intrasequence effects are limited to acoustic similarity.

$$
\text { 9:30-9:45(250) }
$$

Short-Term Interference and Language Change in Texas at El Paso, \& DELOS D. WICKENS, Ohio State University-Proactive interference was shown to build up rapidly over tests that conformed to a Peterson STM paradigm. The present experiment demonstrated that with bilingual Ss, there is a release of inhibition when either the language or the category of the item is changed. When both change, the release is lightly greater than when one changes. 9:45-10:05 (251)

Recognition and Recall in Short-Term Memory. HARLEY A. BERNBACH, Cornell University-Recent theoretical developments about confidence judgments in short-term-memory experiments were used to investigate the difference in the amount of information required in memory for a recall response and for a recognition response. The method permitted examination of the precise nature of the obtained differences in information in memory.

$$
10: 10-10: 25(252)
$$

Noun Imagery and Associative Relatedness in Short-Term Memory. ALLAN PAIVIO \& IAN BEGG, University of Western Ontario-Imagery concreteness and associative relatedness were varied in a STM task. Concrete, high-imagery words were recalled significantly better than abstract words regardless of the level of interitem associative overlap. Thus, contrary to recent proposals, imagery-concreteness effects on recall are not easily 
explained in terms of relatively greater associative interference among abstract words.

10:25-10:35 (253)

Serial Position Curves for Short-Term Memory of Words. STEPHEN KAPPEL, Human Resources Research Office, \& NANCY S. ANDERSON, University of Maryland (read by Nancy S. Anderson-Results are presented for immediate recall of lists of single-syllable words which are vocalized or not during presentation. The results are similar to others in that the shape of the serial-position curve differs as a function of silent or aloud vocalization during visual presentation.

$$
\text { 10:40-10:50 (254) }
$$

Presentation Modality as an Encoding Category in Short-Term Memory. RONALD H. HOPKINS \& JAMES R. GAVELEK, Washington State University-Different word triads were presented on four successive trials. On the fourth trial taxonomic class, presentation modality, neither class nor modality, or both class and modality were changed. A shift in taxonomic class always produced a release from PI. A similar rlease accompanied a change in modality, but only when the shift was from visual to auditory presentation.

$$
10: 55-11: 10(255)
$$

Short-Term Memory for Quantitative Information from Visual Displays. VICKI COHEN, New Mexico State University (sponsored by Richard W. Pew)-Memory for quantitative information from three different visual displays was compared using a Brown-Peterson paradigm with two different interpolated tasks. The digital counter yielded the best recall, followed by the moving pointer and moving scale, in that order. Performance differences under the two interpolated tasks provided evidence for spatial memory.

\section{HUMAN CONDITIONING}

$$
\text { 8:45-9:00 (256) }
$$

Heart-Rate Responses to a Stressor: A Comparison Between Primary and Secondary Psychopaths, and Normal Controls. WALTER D. FENZ, University of Waterloo-Cardiac activity in anticipation of, and in response to, a stressor was assessed in primary and secondary psychopaths, and in a group of control Ss, who were selected on the basis of multiple objective criteria. Reliably group differences were observed, which were interpreted in terms of stimulus deprivation due to institutionalization and the chronic need for stimulation of young psychopaths.

$$
\text { 9:00-9:20 (257) }
$$

Developments with a Mathematical Model for Classical Conditioning. WILLIAM F. PROKASY, University of Utah-A multiple-operator model, with parameters fit separately for each $S$, fit both human and animal conditioning data reasonably well. Analysis of continuous and intermittent reinforcement schedules showed that multiple operators were necessary, that simple reinforcement theory is inappropriate, and that parameter-value patterns were similar for humans and animals.

\section{9:25-9:40 (258)}

Learned Inhibition and Resistance to Extinction. H. D. KIMMEL \& D. W. OWEN, University of South Florida-Ss receiving paired tone-shock GSR conditioning trials were matched on number of trials to peak $C R$ and then given either paired or unpaired postpeak trials (16 tones and 16 shocks). Unexpectedly, the unpaired postpeak group extinguished significantly more rapidly than the paired postpeak group.

$$
\text { 9:40-9:55 (259) }
$$

The UCS-UCR as a Mediator in Differential Eyelid Conditioning. FREDERICK L. NEWMAN, JAMES $R$. FRANCIS, \& ALICE WEST, University of Miami-After establishing differential responding to two tonal CSs (72 trials) a third $\mathrm{CS}\left(\mathrm{CS}_{3}\right)$ was introduced in random sequence with $\mathrm{CS}+$ and $\mathrm{CS}-. \mathrm{CS}_{3}$ was similar to $\mathrm{CS}+$ or $\mathrm{CS}-$ in quality (herz), or percent reinforcement $(0 \%, 20 \%$, or $60 \%$ ), or both. Ss who reliably differentiated CS+ and CS- during the first 72 trials showed reliable $C S$ and reinforcement similarity effects after $\mathrm{CS}_{3}$ was introduced.

\section{0:15-10:25 (260)}

Some Effects of Interpolated Stimuli in Human Eyelid Conditioning. JOHN W. P. OST, Northern Michigan University, BARRY GLASGOW, University of Minnesota, \& DAVID B. VOLCKMANN, Whittier College-Previous findings concerning effects of stimuli interpolated among conditioning trials will be integrated with new evidence drawn from three experiments. While between-group effects are common, within-group effects are infrequent and weak. The significance of these data for the concepts of inhibition and consolidation will be discussed.

$$
\text { 10:25-10:40 (261) }
$$

The Effects of Extraneous Tasks on Human Differential Eyelid Conditioning. MICHAEL NELSON \& LEONARD E. ROSS, University of Wisconsin-Several extraneous tasks were used to mask stimulus contingencies from college $\mathrm{Ss}$ in five differential eyelid conditioning studies. Differential responding was greatly attenuated under one task condition, but to a much lesser extent under others. Viewing silent films decreased differential responding in masked and nonmasked groups.

$$
\text { 10:45-11:00 (262) }
$$

Human Differential Eyelid Conditioning to a CS Intensity Difference. G. ROBERT GRICE, University of New Mexico, KERMIT F. HENRIKSEN, Wisconsin State University, \& JEFFREY M. SPEISS, University of New Mexico-Differential conditioning was obtained in groups with loud or soft tones positive. Acquisition curves were a simple additive combination of stimulus intensity and reinforcement effect. Response to the loud tone when positive in differential conditioning was greater than to the same tone in a $100 \%$ reinforcement condition.

$$
\text { 11:00-11:10(263) }
$$

Conditioning of a Single Motor Unit. ANDREE J. LLOYD \& BRUCE C. LEIBRECHT, U.S. Army Medical Research Lab-Seventeen human Ss were injected with bipolar fine wire electrodes into the tibialis anterior muscle. A start light indicated the onset of a trial. If Ss activated a single motor unit, a correct light appeared. With no additional feedback, Ss learned to isolate and control a single motor unit within 500 trials and demonstrated significant improvement during a relearning series.

$$
\text { 11:15-11:35 (264) }
$$

Escape Conditioning Model of Participation in Conversation. ROBERT FRANK WEISS, University of Oklahoma-Participation in conversation may be reinforced by the opportunity to speak in reply. Latency data from six experiments $(N=680)$ are isomorphic with an instrumental escape conditioning model in demonstrating analogs of (1) acquisition, (2) extinction, (3) partial reinforcement effects, (4) delay of reinforcement effects, (5) Delay by Acquisition Trials effects, (6) drive effects, and correlated reinforcement (DRL) effects.

\section{SPACE PERCEPTION}

$$
\text { 8:45-9:00 (285) }
$$

Shift from Undershooting Toward Overshooting Error Over Repeated Trials with a Body Adjustment Task. A. HARVEY BAKER, Educational Testing Service, \& THEODORE LEVENTHAL, Children's Psychiatric Center of Monmouth County, N.J.-When S's body undergoes rotational movement and $S$ must indicate when it has reached some specified location in space, there is a systematic shift over repeated trials from anticipation error (undershooting) toward habituation error (overshooting), which parallels a shift found in earlier research with visual 
and tactual stimuli.

$$
\text { 9:00-9:20 (286) }
$$

Inflow as a Source of Extraretinal Eye Position Information. ALEXANDER A. SKAVENSKI, University of Maryland (sponsored by Robert $M$. Steinman)-Ss maintained eye position when loads were applied to the eye in total darkness, showing that an inflow signal can be used for extra-retinal oculomotor control. Furthermore, the Ss were aware of the inflow signal and could correctly report the direction of load even when eyelids and conjunctivae were anesthetized.

$$
\text { 9:25-9:40 (287) }
$$

A Reexamination of the Effect of Monaural Stimulation Upon the Perception of Verticality. A. HARVEY BAKER, Educational Testing Service, \& LEONARD CIRILLO \& SEYMOUR WAPNER, Clark University-A classic effect of sensory-tonic theory-viz, apparent verticality shifts opposite the side of monaural sound-has been questioned by others. Data presented here indicate that the effect occurs under the original conditions, but decreases or vanishes under conditions thought to influence the relationship between self and object.

$$
\text { 9:40-9:55 (288) }
$$

Stereoscopic Uncoupling of Edges and Surfaces. W. L. GULICK, Dartmouth College-Contours with uncrossed disparities relative to a frame of reference have been shown to pull surrounding surfaces into stereoseopic depth, even though the surrounding surfaces are themselves bounded by contours that carry no disparity. Surfaces therefore are seen in a plane different from the boundaries that define them. The relationship of this phenomenon to the concept of disparity is explored.

$$
\text { 10:15-10:35 (289) }
$$

The Ponzo Illusion in Stereoscopic Space. ROBERT B.
LAWSON, RONALD T. GREENE, \& CYNTHIA GODEK, University of Vermont-The Ponzo configuration was presented stereoscopically and consisted of a wedge bounding two physically equal vertical lines. Six Os judged the size and distance of the vertical lines, both of which carried equal positive and negative disparities under wedge and no-wedge conditions, using a third line as the module. The Ponzo illusion was not affected by disparity; however, the illusory size changes were not accompanied by appropriate distance changes. Implications of these findings for the size-constancy/perspective-cue explanation of the illusion are discussed.

$$
10: 35-10: 50(290)
$$

Effect of Viewing Distance on a Color Aftereffect Specific to Spatial Frequency. CHARLES S. HARRIS, Bell Telephone Labs, Murray Hill, N.J.-McCollough's orientation-specific color aftereffect is strongest when the retinal width of neutral test stripes approximately matches that of the colored adaptation stripes regardless of viewing distance. Contrary to the expectation for a cortical aftereffect, if "sizescaling" of receptive fjelds occurs in the lateral geniculate (Richards), increasing convergence does not enlarge the optimal width.

$$
\text { 10:55-11:10(291) }
$$

Visual Space: The Size-Distance Relation and Intrinsic Geometry. J. M. FOLEY, UC, Santa Barbara-Experiments on the construction of isosceles right triangles in the show the visual space to be both not it homogeneous. These effects depend on the spatial cues present. They suggest that visual direction and size-distance information are processed independently. 